(c) American Dairy Science Association, 2005.

\title{
In Vitro Peripheral Blood Mononuclear Cell Proliferation in a Crossbred Cattle Population
}

\author{
F. J. Young, ${ }^{1}$ J. A. Woolliams, ${ }^{2}$ J. L. Williams, ${ }^{2}$ E. J. Glass, ${ }^{2}$ \\ R. G. O'Neill, ${ }^{1}$ and J. L. Fitzpatrick ${ }^{3}$ \\ ${ }^{1}$ Division of Animal Production and Public Health, Institute of Comparative Medicine, \\ University of Glasgow Veterinary School, Bearsden Road, Glasgow, UK, G61 1QH \\ ${ }^{2}$ Roslin Institute, Roslin, Midlothian, Edinburgh, UK, EH25 9PS \\ ${ }^{3}$ Moredun Research Institute, Pentlands Science Park, Bush Loan, \\ Midlothian, Edinburgh, UK, EH26 OPZ
}

\begin{abstract}
Immune function measured by Staphylococcus aureus- and phytohemagglutinin- (PHA-) induced cell proliferation was assessed in a population of 445 genetically defined, F2 and backcross Charolais-Holstein crossbred cattle when the animals were approximately 5 mo of age. Variation in Staph. aureus-induced, PHAinduced, and control proliferation [peripheral blood mononuclear cell (PBMC) and media only] was observed at $\mathrm{d} 2,3,4,5,9$, and 10 of in vitro culture. The levels of Staph. aureus-induced, PHA-induced, and control proliferation were strongly positively correlated between days of culture within-assay (e.g., between $\mathrm{d} 2$ and $d 3$ or between $d 4$ and d 5). Responses were also positively correlated when the same individuals were resampled and the assay repeated within 3 mo. Analyses fitting linear mixed models using REML showed that Staph. aureus-induced and PHA-induced proliferation was significantly associated with control proliferation and the year of birth. The age of the animal at sampling influenced only Staph. aureus-induced proliferation, with Staph. aureus-induced proliferation increasing with the age of the animal. Control proliferation was influenced by a sex $\times$ cross interaction, although in this study, sex was confounded by management, as female cattle were housed and reared differently from male cattle. All 3 measures of immune function were influenced by sire, demonstrating that these traits are partially under genetic control, and indicating that it may ultimately be possible to identify quantitative trait loci for these measures of immunity. (Key words: crossbred, restricted maximum likelihood, Staphylococcus aureus, peripheral blood mononuclear cell)
\end{abstract}

Received November 25, 2004.

Accepted March 29, 2005.

Corresponding author: Fiona J. Young; e-mail: Fiona.Young@ dardni.gov.uk

\begin{abstract}
Abbreviation key: $\boldsymbol{B o L A}=$ bovine leukocyte antigen complex, F2 = Holstein-Charolais second cross, HBSS = Hanks' balanced salt solution, $\mathbf{M H C}=$ major histocompatibility complex, PBMC = peripheral blood mononuclear cell, PHA = phytohemagglutinin.
\end{abstract}

\section{INTRODUCTION}

Bovine mastitis remains a major problem to both the dairy (Bradley, 2002) and beef industries (Simpson et al., 1995). In the dairy industry, mastitis affects the quality and quantity of milk and has been identified as one of the most significant causes of economic loss to this agricultural sector worldwide (De Graves and Fetrow, 1993). Studies in dairy cattle have shown that approximately $25 \%$ of cows within UK herds are affected by clinical mastitis at any one time (Kossaibati et al., 1998). Incidence of mastitis has been reported to be between 20 and 40 cases per cow-year within European herds (Heringstad et al., 2000), and 30 to 37 cases per cow-year within herds in the United States (Gardner et al., 1990; Kaneene and Hurd, 1990; Miller and Dorn, 1990). In the United Kingdom, subclinical disease, of which Staphylococcus aureus is the predominant cause (Wilson and Richards, 1980), has been shown to account for a reduction in milk yield of between 2.5 and 6.5\% (Wood and Booth, 1983) and results in premature culling and considerable economic loss. In beef cattle, several studies have highlighted an association between intramammary infections and reduced weight gain in calves (Haggard et al., 1983; Newman et al., 1991). In a study involving more than 300 beef cows, $37 \%$ of cows and $18.1 \%$ of quarters had intramammary infections, and SCC were negatively correlated with calf weaning weights (Watts et al., 1986). However, as extensive management practices are used in rearing beef cattle, there is reduced opportunity for diagnosis of mastitis, and thus, disease incidence may be considerably underestimated in these cows. In beef and dairy cattle, pathogens other than Staph. aureus can be responsible for causing mastitis, with Esche- 
richia coli, Streptococcus uberis, and Streptococcus dysgalactiae the most prevalent in the UK (Wilesmith et al., 1986; Watts et al., 1986).

Breeding for resistance to mammary gland pathogens has the potential to complement traditional therapeutic and prophylactic measures for mastitis, which have had limited success in controlling disease (Detilleux, 2002). Genetic variation in dairy cattle associated with resistance to mastitis was first reviewed in the 1950s (Legates and Grinnells, 1952); however, direct selection of animals for resistance to mastitis has been hampered by the lack of accurate field recording of disease incidence, especially for clinical disease (Mrode et al., 1998). Optimal protection from disease undoubtedly involves many genes and will involve the coordination of aspects of both the innate and acquired immune systems (Malo and Skamene, 1994; Sordillo et al., 1997). In terms of resistance to bovine mastitis, the mammary gland has many forms of defense against invasion by pathogenic organisms, combining nonspecific and specific systems, including anatomical features of the gland and humeral and cellular defense mechanisms (Outteridge and Lee, 1988). In addition, the physiological status of the individual, i.e., pregnancy, puberty, or lactation, has a major influence on the immune response within the mammary gland (Kelm et al., 2001).

Neutrophils, macrophages, lymphocytes, and epithelial cells are normally found in mammary secretions, with the numbers and proportions of these cells varying among individuals and altering throughout lactation (Lee et al., 1980). In spite of the presence of considerable numbers of immune cells within the local mammary gland environment, it has been shown that the mammary gland is generally immunologically compromised compared with systemic responses (Hurley et al., 1990). Indiscriminate ingestion of fat, casein, and other milk components results in less effective phagocytosis by mammary neutrophils and macrophages compared with blood leukocytes (Paape et al., 1981). Therefore, recruitment of cells such as neutrophils from the blood is essential to the defense of the mammary gland (Smits et al., 2000; Paape et al., 2003). Once at the site of infection, neutrophils phagocytose and kill bacterial pathogens (Sordillo et al., 1997). Staphylococci use a number of mechanisms to avoid phagocytosis by invading deep into the mammary gland where they survive and multiply within host phagocytic cells (Sandholm and Mattila, 1986), including neutrophils. Lymphocytes are also critical for host immunity as they respond to infectious agents through elaboration of antibodies, cytokines, and through specific T-cell immunity (Detilleux et al., 1994) and therefore play an essential role in the control of pathogenic invasion of the mammary gland (Kehrli and Goff, 1989). In the mammary gland, both innate and acquired protective factors are coordinated to provide optimal protection from disease (Sordillo et al., 1997) and it is important that both arms of the immune response are considered in selection of future generations of dairy cattle.

Induction of a proliferative response induced by antigen in vitro has been shown to be representative of cellular immunocompetence (Kristensson et al., 1994) and previous studies have shown variation in Staph. aureus-induced proliferative response among commercial Holstein-Friesian cattle, measured by ${ }^{3} \mathrm{H}$-thymidine incorporation in the responding peripheral blood mononuclear cell (PBMC) population (Fitzpatrick et al., 1999; Logan 2001). This measure could potentially be used as an indicator of an individual's ability to mount an immune response to specific pathogens. Variation in individual animals in the T-cell proliferative response to FMDV peptide has been reported (Glass et al., 2000) and additionally, other studies have identified variation among individual cattle in the levels of in vitro $\mathrm{PBMC}$ blastogenesis induced by lectins (Pearson et al., 1979; Schore et al., 1981; Rivas et al., 2002) as a measure of nonspecific immune function. Studies in many species including humans (Hall et al., 2000), mice (Stiffel et al., 1977), chickens (Cheng et al., 1991), and pigs (Wilkie and Mallard, 1999) have investigated the genetic control of immune function, and heritabilities have been reported for PBMC proliferation in lactating dairy cattle when induced by concanavalin A (Kehrli et al., 1991), and in pigs when induced by concanavalin A (Edfors-Lilja et al., 1994) and phytohemagglutinin (PHA; Jensen and Christensen, 1981).

The current study examines the extent of genetic variation for in vitro proliferative response in a large, cross-bred, genetically diverse population that had the potential for widely differing exposures and immune responses to pathogens, in contrast to studies of purebred dairy (Weigel et al., 1991; Detilleux et al., 1995) or beef cattle. Although it could be argued that the measurement of such proliferative responses has only some of the desirable characteristics for implementation (e.g., easily measured, preferably in both sexes at a young age), the existence or otherwise of genetic variation in such traits guides the search for QTL of immune function. Such QTL could be exploited much more easily than measures of immune function in breeding programs to improve livestock production and animal welfare. The results relating to PBMC are presented here; neutrophil responses will be the subject of an additional report.

\section{MATERIALS AND METHODS}

\section{Animals}

The study population was a herd of second-generation Charolais $\times$ Holstein cattle bred at the Roslin Institute 
to identify potential QTL associated with commercially relevant production traits in cattle including meat quality, growth rate, carcass development, and fertility. The herd included 89 Holstein dam backcross, 77 Charolais sire backcross, and 279 Holstein $\times$ Charolais secondcross animals (F2). The progeny were produced using $8 \mathrm{~F} 1$ sires (identified as $\mathrm{A}, \mathrm{B}, \mathrm{C}, \mathrm{D}, \mathrm{E}, \mathrm{F}, \mathrm{G}$, and $\mathrm{H}$ ) and 4 F0 Charolais sires (identified as $\mathrm{W}, \mathrm{X}, \mathrm{Y}$, and Z).

\section{Management}

Four hundred forty-five second-generation crossbred cattle were born and sampled over 4 yr: 55 in 1998, 117 in 1999, 134 in 2000, and 139 in 2001. Male calves ( $\mathrm{n}=$ 236) and female calves $(\mathrm{n}=209)$ were reared under different management systems. Male calves were reared outdoors on pasture with their dams until approximately 5 mo of age, whereas female calves were removed from their dams within $24 \mathrm{~h}$ of birth, housed, and fed milk-replacer. At approximately 5 mo of age, males were weaned from their mothers and housed. Animals were housed in single sex groups, of similar weight. The weight of each animal was monitored throughout the duration of the project and animals were regrouped periodically into similar weight-matched groups. Male calves were slaughtered at approximately $550 \mathrm{~kg}$ and production factors including carcass composition and weight gain were assessed.

\section{Sampling}

Batches of approximately 16 animals per week were blood sampled; $20 \mathrm{~mL}$ of anticoagulated (heparin Vacutainer, 143 USP units, Becton Dickinson, Oxford, UK) blood was collected aseptically from each animal by jugular venipuncture. For management ease and animal handling, test batches were group-based, and thus, the animals sampled within a batch were of a similar weight. Blood samples were processed within $2 \mathrm{~h}$ of collection.

The repeatability of the test was assessed by the repeated sampling of $35 \%$ of the animals, chosen at random, within approximately 3 mo of the initial sampling in each of the first $3 \mathrm{yr}$. This was defined as test 2, with test 1 being the initial sampling of all animals described above.

\section{PBMC Proliferation Assay}

Proliferation of PBMC was measured in vitro. Briefly, the sample was diluted with $10 \mathrm{~mL}$ of Hanks' balanced salt solution without calcium or magnesium (HBSS; Sigma Ltd., Poole, UK), underlaid with $20 \mathrm{~mL}$ of Histopaque 1077 (Sigma), and centrifuged at $700 \times g$ for 40 min at $20^{\circ} \mathrm{C}$. Following centrifugation, the PBMC layer was removed and diluted with HBSS to give a final volume of $50 \mathrm{~mL}$. Following centrifugation at $400 \times g$ for $10 \mathrm{~min}$ at $20^{\circ} \mathrm{C}$, the supernatant was discarded and the cell pellet was resuspended in HBSS. This wash step was repeated 3 more times. Finally, the supernatant was discarded and the cell pellet was resuspended in basal medium Eagles (BME, Gibco Life Technologies Ltd., Paisley, UK). One milliliter of PBMC suspension $\left(4.0 \times 10^{6}\right.$ cells $)$ and $1 \mathrm{~mL}$ of either formalin-fixed Staph. aureus strain NCTC13047 $\left(2.0 \times 10^{8}\right.$ cells $)$, medium, or PHA ( $5 \mu \mathrm{g} / \mathrm{mL}$, Sigma), and $40 \mu \mathrm{L}$ of heat-inactivated autologous serum were added and incubated at $37^{\circ} \mathrm{C}$ with $5 \% \mathrm{CO}_{2}$ over a 10-d period. Autologous serum was used throughout because preliminary investigations showed that background levels of proliferation in the absence of antigen were lower with autologous serum than with commercial fetal calf serum.

On d 2, 3, 4, 5, 9, and 10 of culture, $100-\mu \mathrm{L}$ aliquots were removed in triplicate into 96 -well round-bottomed plates (Bibby Sterilin, Staffordshire, UK), and pulsed with $1 \mu \mathrm{Ci}$ of ${ }^{3} \mathrm{H}$-thymidine per well (Amersham Pharmacia Biotech UK Limited, Amersham, UK) at $37^{\circ} \mathrm{C}$ with $5 \% \mathrm{CO}_{2}$ for $6 \mathrm{~h}$. Following incubation, the 96well plates were removed and stored at $-20^{\circ} \mathrm{C}$ until harvesting. Cells were harvested onto the filter plates from the 96-well plates using a Filtermat 196 Cell Harvester (Canberra Packard Ltd., Berkshire, UK). The harvested cells were washed to remove unincorporated ${ }^{3} \mathrm{H}$-thymidine, and $20 \mu \mathrm{L}$ of scintillation fluid was added. The radioactivity incorporated into the DNA was trapped on the filter, and determined using a Topcount Microplate scintillation and luminescence counter (Canberra Packard). Results were expressed as counts per minute of ${ }^{3} \mathrm{H}$-thymidine incorporation (mean of the triplicates). For the 2001 cohort, the proliferation of PBMC was assessed on d 4 of culture only, a choice that is justified later in this paper.

\section{Statistical Methods}

Preliminary analyses of all raw data used procedures to determine the optimum Box and Cox transformation of the data (Box and Cox, 1964; Minitab, Release 13, Minitab Ltd., UK). This procedure identified logarithmic transformation as optimal. In addition, the preliminary analyses identified that the regression coefficient for control proliferation was not equal to one, on neither the observed scale nor the logarithmic scale. This indicated that the use of change in counts per minute or stimulation indices in the analyses would have been inappropriate. Therefore, the control proliferation of $\mathrm{PBMC}$ in vitro for each individual animal was retained 
within the model as a covariate as described later, and was additionally analyzed as a separate Y-variate.

Linear mixed models were fitted to the natural logarithm of the data using REML procedures in Genstat (6th ed., Lawes Agricultural Trust, Rothamsted, UK). The Y variates analyzed were 1) Staph. aureus-induced PBMC proliferation, 2) PHA-induced PBMC proliferation, and 3) control PBMC proliferation. The linear model was:

$$
\begin{gathered}
\mathrm{Y}_{\mathrm{ijkmnp}}=\mu+\alpha_{\mathrm{i}}+\beta_{\mathrm{j}}+\gamma_{\mathrm{k}}+\delta_{\mathrm{m}}+\kappa\left(\mathrm{c}_{\mathrm{ijkmnp}}-\hat{\mathbf{c}}\right) \\
+\phi\left(\mathrm{s}_{\mathrm{ijkmnp}}-\hat{\mathrm{s}}\right)+\mathrm{u}_{\mathrm{n}}+\mathrm{e}_{\mathrm{ijkmnp}}
\end{gathered}
$$

for calf $p$, with sire $n$, of sex i, breed-cross $j$, born in year $\mathrm{k}$, sampled in batch $\mathrm{m}$, with control proliferation $\mathrm{c}_{\mathrm{ijkmnp}}$, and age $\mathrm{s}_{\mathrm{ijkmnp}}$ at time of sampling, with $\hat{\mathrm{c}}$ and $\hat{s}$ representing the mean control proliferation and mean age of all calves, respectively; where $\mu$ is the fitted mean, $\alpha_{\mathrm{i}}$ is the effect of sex (male and female; $\mathrm{i}=1,2$ ), $\beta_{\mathrm{j}}$ is the effect of breed-cross (Holstein dam backcross, F2, and Charolais sire backcross; $\mathrm{j}=1, \ldots 3), \gamma_{\mathrm{k}}$ is the effect of year of birth $(\mathrm{k}=1, \ldots 4), \delta_{\mathrm{m}}$ is batch of sampling $(\mathrm{m}=1, \ldots 34)$, and where $\kappa$ and $\phi$ are the partial regression coefficients for control proliferation (on a natural logarithm scale) and age at sampling (days), respectively. The regression on control proliferation was omitted when it was itself the Y-variate. The random terms $u_{n}$ and $e_{i j k m n p}$ represent the effects of sire $n$ and the residual error respectively, assumed to have univariate normal distributions with mean 0 and variances $\sigma_{s}^{2}$, and $\sigma_{e}^{2}$, respectively.

Initial models considered all 2-way interactions between the fixed effects, but only those that achieved statistical significance $(P<0.05)$ were retained. Using this approach, the only interaction included in the models was the interaction between sex and cross in the model for control proliferation as a Y-variate. Treating the sampling batch as a random factor, rather than fixed was considered, but examination of the fitted values suggested nonrandom trends within years.

The significance of fixed effects in the model was determined using the Wald test (Wald, 1947). The significance of random effects in the model was determined from log likelihood ratio tests. Heritabilities were calculated using $\mathrm{h}^{2}=4 \frac{\sigma_{s}^{2}}{\sigma_{p}^{2}}$ where the phenotypic variance $\sigma_{p}^{2}$ was estimated as $\sigma_{p}^{2}=\sigma_{s}^{2}+\sigma_{e}^{2}$.

Preliminary analyses examined the profiles and relationships between days but detailed results of the REML analyses for PBMC proliferation induced by Staph. aureus, PHA, and control are presented for d 4 only.

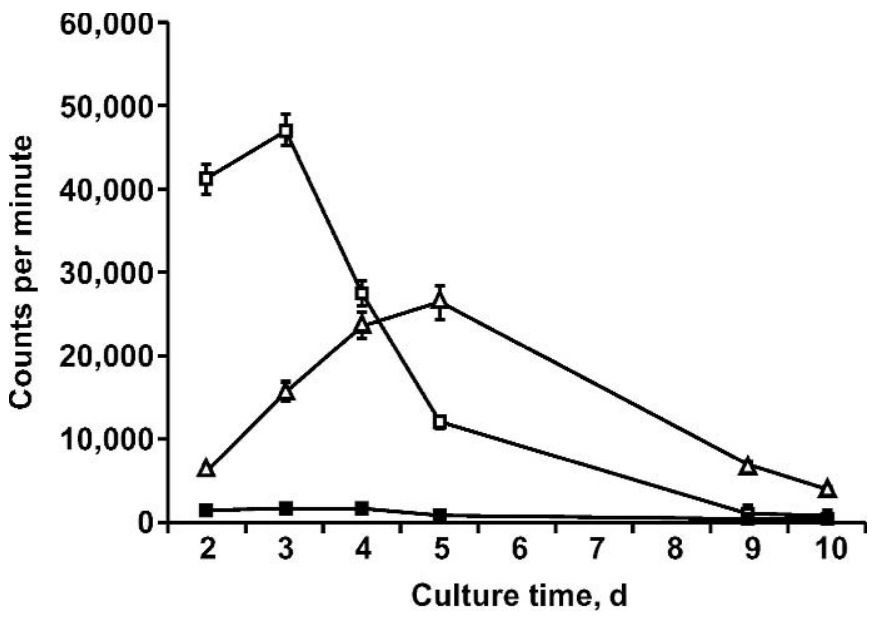

Figure 1. Kinetics of Staphylococcus aureus-induced $(\triangle)$, phytohemagglutinin-induced $(\square)$, and control (ם) in vitro peripheral blood mononuclear cell proliferation (cpm \pm SEM) over $10 \mathrm{~d}$ of culture (1998, 1999, and 2000 cohorts).

\section{RESULTS}

\section{Kinetics of PBMC Proliferation}

The kinetics for Staph. aureus-induced, PHA-induced, and control PBMC proliferation are shown in Figure 1. Considerable variation in Staph. aureusinduced, PHA-induced, and control proliferation of PBMC in vitro was observed among individual animals as indicated by the error bars included in the figure ( \pm SEM). Staphylococcus aureus-induced proliferation was found to peak at d 5 of culture, whereas PHAinduced proliferation was found to peak earlier, at $\mathrm{d} 3$. The largest variation among individual animals was observed on the days of maximal proliferation in Staph. aureus- and PHA-induced cultures. Mean ( \pm SEM) Staph. aureus-induced proliferation was $25,835 \pm 1890$ cpm on d 5 of culture, and the mean PHA-induced proliferation was 46,248 $\pm 1886 \mathrm{cpm}$ on d 3 of culture. By d 9, both Staph. aureus- and PHA-induced proliferation had declined to similar levels as the control. Control proliferation remained relatively low throughout the duration of culture; mean ( \pm SEM) proliferation on $d$ 3 and 5 of culture were $1436 \pm 144$ and $730 \pm 102$ cpm, respectively.

For each of the cultures (i.e., Staph. aureus-induced, PHA-induced, and control), observations of individual time points within the assay were positively correlated. The results for Staph. aureus-induced proliferation are shown in Figure 2. Correlations for each culture were strong among measurements taken on d 2 to 5 inclusive, and between $\mathrm{d} 9$ and 10 . The correlation between different days was at least moderate; and particularly strong for Staph. aureus-induced proliferation, with the high- 


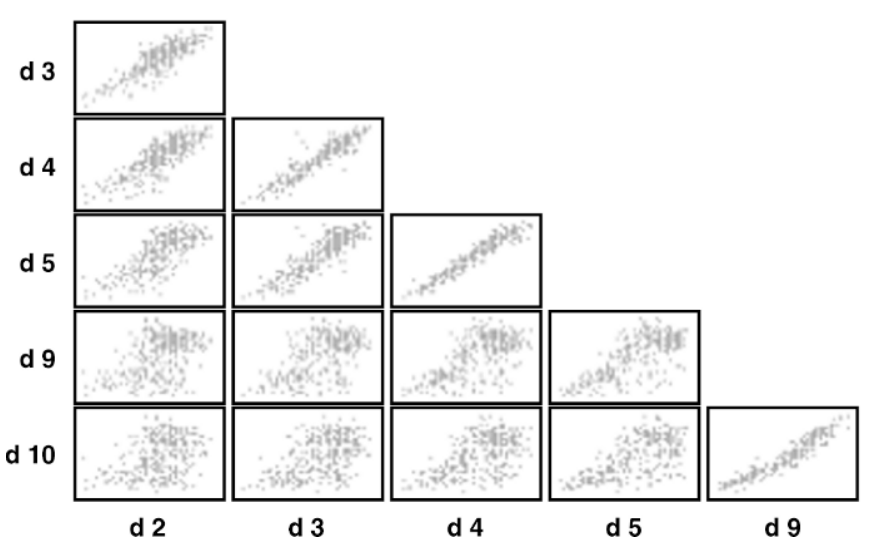

Figure 2. Matrix scatter plot showing correlation of individual animal responses between days of culture for Staphylococcus aureusinduced in vitro peripheral blood mononuclear cell proliferation (1998, 1999 , and 2000 cohorts only). All correlations are significant, $P<$ 0.001 .

est correlation between consecutive days observed between $\mathrm{d} 4$ and 5 (Table 1). The strong correlations among days justified the assessment of proliferation on d 4 only for the 2001 cohort.

Positive correlations were identified between Staph. aureus-induced proliferation and control proliferation on all days of culture, however, the positive correlation decreased over time from $0.68(P<0.001)$ on $d 2$, to $0.27(P<0.001)$ on $\mathrm{d} 4$, and to $0.24(P<0.001)$ on $\mathrm{d} 10$ of culture. The analogous correlations for PHA-induced and control proliferation were lower throughout: 0.19 $(P<0.001)$ on $\mathrm{d} 2,0.34(P<0.001)$ on $\mathrm{d} 4$, and $0.18(P$ $<0.01$ ) on d 10. No significant correlations were found between Staph. aureus-induced proliferation and PHAinduced proliferation on any of the days of in vitro culture.

\section{Correlations Between Test 1 and Test 2 (Same Individuals)}

Staphylococcus aureus-induced and control proliferations were correlated on d $4(0.30,0.32$, respectively, $P$ $<0.05)$ and 5 of culture $(0.34,0.38$, respectively, $P<$ $0.05)$ when the same animals were retested approxi- mately 3 mo after the initial sampling (Table 2). This result indicated that the Staph. aureus-induced and the control proliferation on days of peak proliferation were repeatable for samples taken up to 3 mo apart. A positive correlation $(0.18, P<0.1)$ for PHA-induced proliferation was seen on d 4 of culture. Day 4 , therefore, was identified as the most repeatable day of culture overall for Staph. aureus-induced, PHA-induced, and control $\mathrm{PBMC}$ proliferation and further validated the selection of $d 4$ to assess the 2001 cohort.

\section{REML Analyses}

The results from the comparisons of test 1 and test 2 indicated that responses on $d 4$ and 5 were the most likely to provide information upon the intrinsic attributes of individual animals for Staph. aureus-induced and control proliferation. However, PHA-induced responses, measured on d 4, although not statistically significant, showed a greater correlation than on d 5 . Results of REML analyses have therefore been presented for $\mathrm{d} 4$ alone. This allowed more data to be included and the correlations of variation on $\mathrm{d} 4 \mathrm{with}$ the variation observed at peak response ( 3 for PHA, d 5 for Staph. aureus) were high.

\section{Control PBMC Proliferation}

The control PBMC proliferation had a phenotypic variance of 1.11 on the natural logarithmic scale, which was indicative of the high coefficient of variation (CV) on the observed scale. Variation among sires, implicitly additive genetic variation, formed a substantial component of the total variance, with an estimated heritability of 0.35 (SE $0.20 ; P<0.001$ ). There was significant interaction between breed-cross and the sex of the individual $(P<0.05)$; for all breed-cross types, males had a greater mean proliferation in the control samples than females, but this difference was greatest for the F2 and least for the backcross Charolais. The design cannot separate the influence of sex and the environment in which the sex was kept due to confounding between these fixed effects.

Table 1. Correlations between consecutive days for the proliferation of peripheral blood mononuclear cell (PBMC) proliferation induced by Staphylococcus aureus, phytohemagglutinin (PHA), and control in test 1. All correlations are significant $(P<0.001)$.

\begin{tabular}{llllll}
\hline & \multicolumn{5}{c}{ Correlation between culture days } \\
\cline { 2 - 6 } PBMC proliferation & $\mathrm{d} 2 / \mathrm{d} 3$ & $\mathrm{~d} \mathrm{3/d} \mathrm{4}$ & $\mathrm{d} \mathrm{4/d} \mathrm{5}$ & $\mathrm{d} 5 / \mathrm{d} 9$ & $\mathrm{~d} 9 / \mathrm{d} 10$ \\
\hline Staph. aureus & 0.862 & 0.931 & 0.968 & 0.729 & 0.958 \\
PHA & 0.641 & 0.758 & 0.885 & 0.508 & 0.868 \\
Control & 0.742 & 0.867 & 0.914 & 0.505 & 0.750 \\
\hline
\end{tabular}


Table 2. Correlations among individuals for homologous assay days for test 1 (d 2, 3, 4, 5, 9, and 10) and test 2 (repeat d (Rd) 2, 3, 4, 5, 9, and 10) when sampling was repeated after approximately 3 mo.

\begin{tabular}{lllllrc}
\hline & \multicolumn{5}{c}{ Correlations between test 1 and test 2} \\
\cline { 2 - 7 } PBMC proliferation & $\mathrm{d} 2 / \mathrm{Rd} 2$ & $\mathrm{~d}$ 3/Rd 3 & $\mathrm{~d}$ 4/Rd 4 & $\mathrm{d} 5 / \mathrm{Rd} 5$ & $\mathrm{~d}$ 9/Rd 9 & $\mathrm{~d} 10 / \mathrm{Rd} 10$ \\
\hline Staphylococcus aureus & 0.124 & $0.017^{* *}$ & $0.296^{*}$ & $0.346^{*}$ & 0.005 & 0.005 \\
Phytohemagglutinin & 0.125 & 0.120 & $0.178^{* *}$ & 0.095 & -0.016 & 0.136 \\
Control & 0.024 & 0.127 & $0.317^{*}$ & $0.384^{*}$ & 0.037 & -0.027 \\
\hline
\end{tabular}

$* P<0.005 ; * * P<0.10$

\section{Staph. aureus-Induced PBMC Proliferation}

The total phenotypic variance for the trait on the natural logarithmic scale was $1.16(\mathrm{SE}=0.09)$, indicative of a large CV on the observed scale. There was no significant association of the type of breed-cross on the levels of Staph. aureus-induced proliferation, but a significant association of sire was identified $(P<0.01)$ with an estimate of trait heritability of $0.20(\mathrm{SE}=0.14)$. In general, the levels of Staph. aureus-induced proliferation increased with the age of the individual animal assessed in the current study with a regression coefficient on the natural logarithmic scale of 0.0067 (SE $=$ $0.0030 ; P<0.05)$. On d 4 of culture in the whole data set, an increase of $7 \mathrm{~d}$ in the age of the individual animals sampled was associated with a $4.8 \%$ increase in the levels of Staph. aureus-induced proliferation. A systematic reduction occurred in the levels of Staph. aureusinduced proliferation between the sampling years $(P<$ $0.001)$. There was no evidence for differences between males and females, which were confounded with the management. The level of control proliferation had a positive significant association with the levels of Staph. aureus-induced PBMC proliferation with a regression coefficient of $0.42(\mathrm{SE}=0.05 ; P<0.001)$; this is distinctly different from one that would be implicit in the analyses of a stimulation index. Therefore, greater proliferation was observed in samples with greater control values, but a doubling of the control only increased the proliferation by $34 \%$.

\section{PHA-Induced PBMC Proliferation}

The total phenotypic variance for the trait on a natural logarithmic scale was $0.83(\mathrm{SE}=0.06)$, smaller than for Staph. aureus-induced proliferation but still indicative of a large CV on the observed scale. The sire was significantly associated with the levels of PHA-induced PBMC proliferation $(P<0.01)$, with a trait heritability of 0.18 ( $\mathrm{SE}=0.13$ ), but there was no evidence of an effect of the type of cross $(P>0.05)$. Although there was no obvious trend, the year of birth was found to influence PHA-induced proliferation $(P<0.001)$. In common with Staph. aureus, there was no evidence for a difference based on the confounded effects of sex and management. In addition, control proliferation was significantly positively associated with the levels of PHAinduced PBMC proliferation $(P<0.001)$, but the regression coefficient $0.21(\mathrm{SE}=0.04 ; P<0.001)$ was lower than for Staph. aureus-induced proliferation, with a doubling of the control predicted to increase PHA-induced proliferation by $16 \%$.

\section{DISCUSSION}

The results of the REML analyses identified year of birth and sire as the main significant factors affecting all 3 responses measured: Staph. aureus-induced, PHAinduced, and control proliferation. The control proliferation in the absence of antigen was itself a significant predictor of Staph. aureus- and PHA-induced proliferations, but age at sampling was only observed to influence Staph. aureus proliferation. Previous studies aimed at assessing immune function in cattle have generally been carried out on small numbers in females, and in dairy rather than beef cattle (e.g., Weigel et al., 1991; Detilleux et al., 1995). The current study involved assessing a wide variety of PBMC-related immune responses in a large number of male and female animals, with known and mixed genetic background, at approximately the same age.

The immune system has evolved in many complex ways to deal with infection by pathogens (Engelhard, 1994). To be effective and reliable, multiple defense systems must be available. Defense of the mammary gland against mastitis-causing pathogens is mediated by anatomical, cellular, and soluble protective factors; specifically, innate and acquired immune factors, all of which play vital roles in protecting the gland from infectious disease (Sordillo et al., 1997). Despite the presence of considerable numbers of immune cells in the local mammary gland environment, it has been shown that mammary gland immunity is generally compromised when compared with systemic immunity (Hurley et al., 1990). Previous studies identified a number of problems in assessing the function of cells isolated from milk (Paape et al., 2003). It was appropriate therefore to measure the response of immune cells isolated 
from the systemic circulation, due to the well-documented trafficking of lymphocyte populations, which is essential to adaptive immunity and is shared with the peripheral system rather than the common mucosal system (Kehrli and Harp, 2001). Assessment of the proliferative responses of PBMC in cattle may provide an indirect indicator of immune function of antigen-driven cellular responses in the local mammary glands of cows, and thus, an indicator of general immune competence in bulls.

In the current study, a component of the variation in Staph. aureus-induced proliferation was a repeatable attribute of the animal, as there was a moderate correlation between tests 1 and 2 . It is possible that the maturation of the juvenile immune system (Wilson et al., 1996) will account for this relatively modest correlation, as reflected in the relationship with age within test 1, for Staph. aureus-induced proliferation. The possibility that this correlation resulted from increased numbers of Staph. aureus-specific cells due to exposure to this prevalent pathogen (Roberson et al., 1994; Cullor and Tyler, 1996) argues that the Staph. aureus-induced proliferation is merely the result of the environmental exposure. The results from the genetic analyses in this study suggest this is not the sole cause; nevertheless, the correlations between days of culture within-assay (i.e., between $\mathrm{d} 4$ and d 5) and between-assay (i.e., test 1 and test 2) do provide support for Staph. aureusinduced proliferation as a valid tool for assessment of immune function.

Variation among individual cattle was observed in the in vitro culture around peak proliferation for both Staph. aureus-induced and PHA-induced cultures. Various factors can influence individual variability in the intensity of a proliferative immune response induced by a specific antigen including hormone levels (Hooper et al., 1987), and the composition of the cellular subpopulations in PBMC (Lutje and Black, 1991). Of potential relevance to this paper, Park et al. (2004) identified a link between the CD4:CD8 T-cell subset ratio in PBMC and susceptibility to clinical mastitis. Variation in proliferative response may be associated with the numbers of memory T cells present in an individual, and thus, may be regulated by prior exposure to that particular antigen (Park et al., 1993; Wilson et al., 1996). Further investigation of the cell subpopulations involved in the proliferative responses described here is warranted.

Nonetheless, the genetic variation observed, identified via the sire component of variance, supports the hypothesis that a component of the variation is an inherent attribute of the animal. The heritability estimates for all 3 traits are low to moderate, which is consistent with the moderate correlations across time. However, the magnitudes of the heritabilities are not a barrier to implementation within dairy improvement schemes because progress has been achieved with traits of lower heritability.

The genes underlying the observed heritabilities may include those of the major histocompatibility complex (MHC), because variation in proliferative response may also be associated with MHC haplotype. Glass et al. (2000) suggested that cattle with duplicated DQ haplotypes, located within the bovine MHC (bovine leukocyte antigen complex, BoLA) class IIa region, may be able to produce higher responses to antigens than cattle with single DQ haplotypes. Subsequently, Park et al. (2004) concluded that susceptibility to mastitis in cattle was associated with MHC haplotypes that have only a single set of DQ genes. There is a considerable canon of published studies reporting associations between bovine MHC and mastitis, but even the largest study on bovine MHC class I found inconsistent results within subsets of the data (Mejdell et al., 1994). Nonetheless, the MHC has been shown to be a major genetic component of infectious or autoimmune disease resistance or susceptibility in a variety of species (Klein, 1986; Tizard, 2000). Associations between bovine MHC class II alleles and bull breeding have been shown with respect to many conditions of dairy cattle including clinical mastitis, ketosis, retention of the placenta, and milk fever (Lunden et al., 1991). A recent study in the Canadian Holstein suggested the MHC II haplotype DRB3.2*23 conferred an increased susceptibility to mastitis, with DRB3.2*16 conferring a decreased risk (Sharif et al., 1998). The study by Sharif et al. (1998) graded the level of mastitis that occurred in these animals and identified the pathogens responsible for the cases within the grades. The identification of the causative agent of diseases is an essential aspect of the identification of resistant or susceptible $B o L A$ alleles because the influence of the BoLA alleles on immune function may differ between disease-causing pathogens (Dietz et al., 1997). This is particularly important with mastitis where multiple pathogens have been shown to be involved. Further investigation of $\mathrm{MHC}$ haplotypes would allow more accurate assumptions of genetic correlations and control of immune function to be made.

The in vitro tests described here could provide indicators of general immune competence, but no significant correlation was observed between Staph. aureus- and PHA-induced responses. It therefore seems likely that the genetic influences on the variation observed for Staph. aureus- and PHA-induced proliferative responses are different, which may reflect the very different processes involved in cell stimulation by mitogens and antigens, as evidenced by the differential transcriptional responses of PBMC to PHA and to a specific antigen (Diaz-Mitoma et al., 2004). 
The immune system is affected by both environmental and genetic factors (Nguyen, 1984). The significant effect of sire and heritability estimates identified for Staph. aureus-induced, PHA-induced, and control PBMC proliferation in this study highlight the importance of genetic control of PBMC-related immune function. Whereas other studies by Tempelman et al. (2002) and Saama et al. (2004) have identified a range of heritability estimates for many general aspects of neutrophil and PBMC immunocompetence in dairy bulls, the current study indicates the potential for identification of bulls whose progeny have superior PBMC responses induced by specific immune stimuli, including to a bacterium that contributes to the pathogenesis of mastitis. The long-term aim is to produce cattle with high production potential with sufficient resistance to commonly occurring diseases to permit fulfillment of their potential and maximize economic returns.

\section{CONCLUSIONS}

Staphylococcus aureus- and PHA-induced in vitro assays were developed which identified significant influences on several aspects of PBMC-related immune function in a crossbred population of cattle. Assessment of potential immune responses to infection in 445 crossbred cattle identified variation among individual animals in their in vitro PBMC proliferative responses induced by Staph. aureus and PHA, as well as variation in control PBMC proliferation (PBMC and media only). Statistical analyses identified control proliferation, year of birth, age of the animal at sampling, and sire to be of significant influence. In particular, the sireinfluenced variation may predict PBMC-related immune response to infection and allow improvements in animal health and welfare by breeding animals with increased resistance to important pathogens such as Staph. aureus. This particular study may aid in the interpretation of one aspect of a very complex system of defense of the bovine mammary gland, which relies on interactions between innate and acquired immune parameters.

\section{ACKNOWLEDGMENTS}

We acknowledge The Biotechnology and Biological Sciences Research Council, Department of Environment Food and Rural Affairs, Milk Development Council, Meat and Livestock Commission, and Scottish Executive Environment and Rural Affairs Department for funding this project.

\section{REFERENCES}

Box, G. E. P., and D. R. Cox. 1964. An analysis of transformations. J. R. Stat. Soc. B. 26:211-252.
Bradley, A. J. 2002. Bovine mastitis: An evolving disease. Vet. J. 164:116-128.

Cheng, S., M. F. Rothschild, and S. J. Lamont. 1991. Estimates of quantitative genetic parameters of immunologic traits in the chicken. Poult. Sci. 70:2023-2027.

Cullor, J. S., and J. W. Tyler. 1996. Mammary gland health and disorders. Pages 1178-1193 in Large Animal Internal Medicine. 2nd ed. P. Smith Bradford, ed. Mosby, St. Louis, MO.

DeGraves, F. J., and J. Fetrow. 1993. Economics of mastitis and mastitis control. Vet. Clin. North Am. Food Anim. Pract. 9:421-434.

Detilleux, J. C. 2002. Genetic factors affecting susceptibility of dairy cows to udder pathogens. Vet. Immunol. Immunopathol. 88:103-110.

Detilleux, J. C., M. E. Kehrli, A. E. Freeman, L. K. Fox, and D. H. Kelley. 1995. Mastitis of periparturient Holstein cattle-A phenotypic and genetic study. J. Dairy Sci. 78:2285-2293.

Detilleux, J. C., K. J. Koehler, A. E. Freeman, M. E. Kehrli, Jr., and D. H. Kelley. 1994. Immunological parameters of periparturient Holstein cattle: Genetic variation. J. Dairy Sci. 77:2640-2650.

Diaz-Mitoma, F., I. Alvarez-Maya, A. Dabrowski, J. Jaffey, R. Frost, S. Aucoin, M. Kryworuchko, M. Lapner, H. Tadesse, and A. Giulivi. 2004. Transcriptional analysis of human peripheral blood mononuclear cells after influenza immunization. J. Clin. Virol. 31:100-112.

Dietz, A. B., J. C. Detilleux, A. E. Freeman, D. H. Kelley, J. R. Stabel, and M. E. Kehrli. 1997. Genetic association of bovine lymphocyte antigen DRB3 alleles with immunological traits of Holstein cattle. J. Dairy Sci. 80:400-405.

Edfors-Lilja, I., E. Wattrang, U. Magnusson, and C. Fossum. 1994. Genetic variation in parameters reflecting immune competence of swine. Vet. Immunol. Immunopathol. 40:1-16.

Engelhard, V. H. 1994. How cells process antigens. Sci. Am. 271:54-61.

Fitzpatrick, J. L., K. E. Logan, F. J. Young, M. J. Stear, D. J. Platt, and B. J. McGuirk. 1999. Breeding cattle for mastitis resistance. Page 46-53 in Proceedings of the British Mastitis Conference, Stoneleigh, UK. Institute for Animal Health, Compton, UK.

Gardner, I. A., D. H. Hird, W. W. Utterback, C. Danaye-Elmi, B. R. Heron, K. H. Cristiansen, and W. M. Sischo. 1990. Mortality, morbidity, case-fatality, and culling rates for Californian dairy cattle as evaluated by the National Health Monitoring System, 1986-1987. Prev. Vet. Med. 8:157-170.

Glass, E. J., R. A. Oliver, and G. C. Russell. 2000. Duplicated DQ haplotypes increase the complexity of restriction element usage in cattle. J. Immunol. 165:134-138.

Haggard, D. L., J. Farsworth, and J. A. Springer. 1983. Subclinical mastitis in beef cows. JAVMA 182:604-606.

Hall, M. S., K. R. Ahmadi, P. Norman, H. Snieder, A. J. MacGregor, R. W. Vaughan, T. D. Spector, and J. S. Lanchbury. 2000. Genetic influence on peripheral blood T lymphocyte levels. Genes Immun. $1: 423-427$.

Heringstad, B., G. Klemetsdal, and J. Ruane. 2000. Selection for mastitis resistance in dairy cattle: A review with focus on the situation in the Nordic countries. Livest. Prod. Sci. 64:95-106.

Hooper, D. C., D. H. Chantry, and W. D. Billington. 1987. Murine pregnancy-associated modulations in lymphocyte reactivity to mitogens-Identification of the cell populations affected. J. Reprod. Immunol. 11:273-286.

Hurley, D. J., M. H. Kensinger, A. M. Mastro, and R. A. Wilson. 1990. An evaluation of the mononuclear cells derived from bovine mammary gland dry secretions using leukocyte antigen specific monoclonal antibodies, light-scattering properties and non-specific esterase staining. Vet. Immunol. Immunopathol. 25:177-193.

Jensen, P. T., and K. Christensen. 1981. Genetic studies on the in vitro PHA-transformation of porcine blood lymphocytes. Vet. Immunol. Immunopathol. 2:133-143.

Kaneene, J. B., and H. S. Hurd. 1990. The National animal health monitoring system in Michigan. I. Design, data and frequencies of selected diary cattle diseases. Prev. Vet. Med. 8:103-114. 
Kehrli, M. E., and J. P. Goff. 1989. Periparturient hypocalcaemia in cows-Effects on peripheral-blood neutrophil and lymphocyte function. J. Dairy Sci. 72:1188-1196.

Kehrli, M. E., and J. A. Harp. 2001. Immunity in the mammary gland. Vet. Clin. North Am. Food Anim. Pract. 17:496-516.

Kehrli, M. E., K. A. Weigel, A. E. Freeman, J. R. Thurston, and D. H. Kelley. 1991. Bovine sire effects on daughters in vitro blood neutrophil functions, lymphocyte blastogenesis, serum complement and conglutinin levels. Vet. Immunol. Immunopathol. 27:303-319.

Kelm, S. C., A. E. Freeman, and M. E. Kehrli. 2001. Genetic control of disease resistance and immunoresponsiveness. Vet. Clin. North Am. Food Anim. Pract. 17:477-493.

Klein, J. 1986. Antigen major histocompatibility complex T cell receptors: Inquiries into the immunological ménage a trois. Immunol. Res. 5:173-190.

Kossaibati, M. A., M. Hovi, and R. J. Esslemont. 1998. Incidence of clinical mastitis in dairy herds in England. Vet. Rec. 143:649-653.

Kristensson, K., L. Kristensen, C. A. K. Borrebaeck, and R. Carlsson. 1994. Activation of human CD4(+)45RA(+) T-cells using B-cells as accessory cells. Immunol. Lett. 39:223-229.

Lee, C. S., F. B. P. Wooding, and P. Kemp. 1980. Identification, properties, and differential counts of cell populations using electron microscopy of dry cows secretions, colostrums and milk from normal cows. J. Dairy Res. 47:39-50.

Legates, J. E., and C. D. Grinnells. 1952. Genetic relationships in resistance to mastitis in dairy cattle. J. Dairy Sci. 35:829-833.

Logan, K. E. 2001. Immunological responses of Holstein-Friesian cattle to Staphylococcus aureus in vitro. Ph.D. thesis, University of Glasgow, UK.

Lunden, A., S. Sigurdardottir, and L. Andersson. 1991. Restriction fragment length polymorphism of a bovine T-cell receptor beta gene. Anim. Genet. 22:497-501.

Lutje, V., and S. J. Black. 1991. Cellular interactions regulating the in vitro response of bovine lymphocytes to ovalbumin. Vet. Immunol. Immunopathol. 28:275-288.

Malo, D., and E. Skamene. 1994. Genetic control of host resistance to infection. Trends Genet. 10:365-371.

Mejdell, C. M., O. Lie, E. E. Arnet, and R. L. Spooner. 1994. Association of major histocompatibility complex antigens (BoLA-A) with AI bull progeny test results for mastitis, ketosis and fertility in Norwegian cattle. Anim. Genet. 25:99-104.

Miller, G. Y., and C. R. Dorn. 1990. Costs of dairy cattle diseases to producers in Ohio. Prev. Vet. Med. 8:171-182.

Mrode, R. A., G. J. T. Swanson, and M. S. Winter. 1998. Genetic parameters and evaluations for somatic cell counts and its relationship with production and type traits in some dairy breeds in the United Kingdom. Anim. Sci. 66:569-576.

Newman, M. A., L. L. Wilson, E. H. Cash, R. J. Eberhart, and T. R. Drake. 1991. Mastitis in beef cows and its effects on calf weight gain. J. Anim. Sci. 69:4259-4272.

Nguyen, T. C. 1984. The immune response in sheep: Analysis of age, sex and genetic effects on the quantitative antibody response to chicken red blood cells. Vet. Immunol. Immunopathol. 5:237-245.

Outteridge, P. M., and C. S. Lee. 1988. The defense mechanisms of the mammary gland of domestic ruminants. Prog. Vet. Microbiol. Immunol. 4:165-169.

Paape, M. J., D. D. Bannerman, X. Zhao, and J. W. Lee. 2003. The bovine neutrophil: Structure and function in blood and milk. Vet. Res. 34:597-627.

Paape, M. J., W. P. Wergin, and A. J. Guidry. 1981. Phagocytic defense of the ruminant mammary gland. Adv. Exp. Med. Biol. 137:555-578.

Park, Y. H., L. K. Fox, M. J. Hamilton, and W. C. Davis. 1993. Suppression of proliferative response of BoCD4+ T lymphocytes by activated BoCD8+ T lymphocytes in the mammary gland of cows with Staphylococcus aureus mastitis. Vet. Immunol. Immunopathol. 36:137-151.

Park, Y. H., Y. S. Joo, J. Y. Park, J. S. Moon, S. H. Kim, N. H. Kwon, J. S. Ahn, W. C. Davis, and C. J. Davis. 2004. Characterization of lymphocyte subpopulations and major histocompatibility complex haplotypes of mastitis resistant and susceptible cows. J. Vet. Sci. 5:29-39.

Pearson, T. W., G. E. Roelants, L. B. Lundin, and K. S. Mayor-Withey. 1979. The bovine lymphoid system: Binding and stimulation of peripheral blood lymphocytes by lectins. J. Immunol. Methods 26:271-282.

Rivas, A. L., R. Tadevosyan, F. W. Quimby, and D. H. Lein. 2002. Blood and milk cellular immune responses of mastitic non-periparturient cows inoculated with Staphylococcus aureus. Can. J. Vet. Res. 66:125-131.

Roberson, J. R., L. K. Fox, D. D. Hannock, J. M. Gay, and T. E. Besser. 1994. Ecology of Staphylococcus aureus isolated from various sites on dairy farms. J. Dairy Sci. 77:3354-3364.

Saama, P. M., J. B. Jacob, M. E. Kehrli, A. E. Freeman, S. C. Kelm, A. L. Kuck, R. J. Tempelman, and J. L. Burton. 2004. Genetic variation in bovine mononuclear leukocyte responses to dexamethasone. J. Dairy Sci. 87:3928-3937.

Sandholm, M., and T. Mattila. 1986. Biochemical aspects of bovine mastitis. Isr. J. Vet. Med. 42:405-415.

Schore, C. E., B. I. Osburn, D. E. Jasper, and D. E. Tyler. 1981. Blymphocytes and T-lymphocytes in the bovine mammary gland rosette. Vet. Immunol. Immunopathol. 2:561-569.

Sharif, S., B. A. Mallard, B. N. Wilkie, J. M. Sargeant, H. M. Scott, J. C. M. Dekkers, and K. E. Leslie. 1998. Associations of the bovine major histocompatibility complex DRB3 (BoLA-DRB3) alleles with occurrence of disease and milk somatic cell score in Canadian dairy cattle. Anim. Genet. 29:185-193.

Simpson, R. B., D. P. Wesen, K. L. Anderson, J. D. Armstrong, and R. W. Harvey. 1995. Subclinical mastitis and milk production in primiparous Simmental cows. J. Anim. Sci. 73:1552-1558.

Smits, E., C. Burvenich, A. J. Guidry, and A. Massart-Leen. 2000. Adhesion receptor $\mathrm{CD} 11 \mathrm{~b} / \mathrm{CD} 18$ contributes to neutrophil diapedesis across the bovine blood-milk barrier. Vet. Immunol. Immunopathol. 73:255-265.

Sordillo, L. M., K. Shafer-Weaver, and D. DeRosa. 1997. Immunobiology of the mammary gland. J. Dairy Sci. 80:1851-1865.

Stiffel, C., M. Liacopoulos-Briot, C. Decreusefond, and F. Lambert. 1977. Genetic selection of mice for quantitative responsiveness of lymphocytes to phytohaemagglutinin. Eur. J. Immunol. 7:291-297.

Tempelman, R. J., P. M. Saama, A. E. Freeman, S. C. Kelm, A. L. Kuck, M. E. Kerhli, and J. L. Burton. 2002. Genetic variation in bovine neutrophil sensitivity to glucocorticoid challenge. Acta Agric. Scand. A Anim. Sci. 52:189-202.

Tizard, I. R. 2000. Veterinary immunology: An introduction. W. B. Saunders, Philadelphia, PA.

Wald, A. 1947, Sequential Analysis. 1st ed, John Wiley and Sons, New York, NY.

Watts, J. L., J. W. Pankey, W. M. Oliver, S. C. Nickerson, and A. W. Lazarus. 1986. Prevalence and effects of intramammary infection in beef cows. J. Anim. Sci. 62:16-20.

Weigel, K. A., M. E. Kehrli, A. E. Freeman, J. R. Thurston, M. J. Stear, and D. H. Kelley. 1991. Association of Class-I bovine lymphocyte antigen complex alleles with in vitro blood neutrophil functions, lymphocyte blastogenesis, serum complement and conglutinin levels in dairy cattle. Vet. Immunol. Immunopathol. 27:321-335.

Wilesmith, J. W., P. G. Francis, and C. D. Wilson. 1986. Incidence of clinical mastitis in a cohort of British dairy herds. Vet. Rec. 118:199-204.

Wilkie, B., and B. Mallard. 1999. Selection for high immune response: An alternative approach to animal health maintenance? Vet. Immunol. Immunopathol. 72:231-235.

Wilson, C. D., and M. S. Richards. 1980. A survey of mastitis in the British dairy herd. Vet. Rec. 106:431-435.

Wilson, R. A., A. Zolnai, P. Rudas, and L. V. Freyno. 1996. T-cell subsets in blood and lymphoid tissues obtained from fetal calves, maturing calves, and adult bovines. Vet. Immunol. Immunopathol. 53:49-60.

Wood, P. D. P., and J. M. Booth. 1983. Variation in milk cell counts during lactation of British Friesian cows. Anim. Prod. 36:335-339. 